\title{
Incorporating graphene oxide into lime solution: A study of flocculation and corresponding improvement
}

\author{
G.J. Jing ${ }^{\mathrm{a}}$, Z.M. Ye ${ }^{\mathrm{a}} \bowtie$, X.L. Lu ${ }^{\mathrm{a}}$, J.M. Wu' ${ }^{\mathrm{a}}$, S.X. Wang ${ }^{\mathrm{a}}$, X. Cheng ${ }^{\mathrm{b}}$ \\ a. School of Materials Science \& Engineering, University of Jinan, (Jinan, China) \\ b. Shandong Provincial Key Laboratory of Preparation and Measurement of Building Materials, (Jinan, China) \\ \mse_yezm@163.com
}

\begin{abstract}
The dispersion behavior of graphene oxide in cement matrix is one important factor in enhancing cement performance. In this work, we investigated the dispersion of graphene oxide in cement by simulating alkaline environment with a solution of calcium hydroxide and studied the corresponding strategy of improving dispersion. The obtained results showed that graphene oxide would flocculate even if calcium hydroxide concentration was very low, which might be the main reason of the unstable properties of the graphene oxidedoped cement. In addition, we discovered that, compared to -OH group, the - $\mathrm{COOH}$ group and the long chain of polycarboxylate-based superplasticizer were more effective in delaying the flocculation of graphene oxide. Finally, we proposed a dispersion mechanism of polycarboxylate-based superplasticizer. The study provides inspiration for the design of graphene oxide-doped cement materials.
\end{abstract}

KEYWORDS: Portland cement; Reaction; Lime; Dispersion; Superplasticizers

Citation/Citar como: Jing, G.J.; Ye, Z.M.; Lu, X.L.; Wu, J.M.; Wang, S.X.; Cheng, X. (2018) Incorporating graphene oxide into lime solution: A study of flocculation and corresponding improvement. Mater. Construcc. 68 [331], e165 https://doi.org/10.3989/mc.2018.05217

RESUMEN: Incorporación de óxido de grafeno en una solución de cal. Estudio de la floculación y de la mejora correspondiente. La posible dispersión que el óxido de grafeno pueda inducir en matrices de cemento es un factor importante a considerar para mejorar el rendimiento del cemento. En este trabajo, se ha investigado la dispersión de óxido de grafeno en cemento simulando el ambiente alcalino con una solución del hidróxido de calcio, estudiando las estrategias correspondientes para mejorar el grado de dispersión. Los resultados obtenidos mostraron que el óxido de grafeno flocula incluso cuando la concentración de hidróxido de calcio es muy baja, lo que podría ser la razón principal de las características inestables del cemento dopado con óxido de grafeno. Además, se ha determinado que, en contraste con los grupos $\mathrm{OH}$, los grupos $\mathrm{COOH}$ y las largas cadenas de los aditivos superplastificantes basados en policarboxilatos retrasan dicha floculación. Finalmente, se propone un mecanismo de dispersión de dichos aditivos superplastificantes basados en policarboxilatos. Este estudio proporciona una base para el diseño de materiales de cemento dopados con óxido de grafeno.

PALABRAS CLAVE: Cemento Portland; Reacción; Cal; Dispersión; Superplastificantes

ORCID ID: G.J. Jing (http://orcid.org/0000-0002-5755-4341); Z.M. Ye (http://orcid.org/0000-0002-2638-9750); X.L. Lu (http://orcid.org/0000-0002-0953-9219); J.M. Wu (http://orcid.org/0000-0002-8005-0977); S.X. Wang (http:// orcid.org/0000-0003-4995-7324); X. Cheng (http://orcid.org/0000-0002-6649-7959)

Copyright: (C) 2018 CSIC. This is an open-access article distributed under the terms of the Creative Commons Attribution 4.0 International (CC BY 4.0) License 


\section{INTRODUCTION}

In recent years, several attempts have been made to enhance the mechanical, electrical and transport properties of cement by introducing graphene oxide (GO). Gong et al. (1) demonstrated that the mechanical properties of hardened cement paste were improved by the addition of GO and the compressive and tensile strength exhibited a distinct increase by approximately $40 \%$. Pan et al. (2) showed that the incorporation of GO (0.05 wt. \%) into cement could improve the compressive and flexural strength by approximately $33 \%$ and $59 \%$, respectively. The transport properties of cement containing GO were studied (3). The results revealed that cement mixed with GO showed a lower chloride penetration depth and water absorption compared with the reference samples. Moreover, Rhee et al. (4) showed that the cement mortar including GO exhibited a moderate electrical conductivity among other carbon nanomaterials such as carbon nanotubes and carbon fibers. The applying of GO not only offers extraordinary properties of cement but also contributes to decreasing maintenance costs. Although an increase in cost occurs compared with common cement, GO is explored as a promising additive for reinforcements in cement-based materials. However, it should be noted that the properties of cement with consistent GO contents are diverse. This is possibly attributed to the poor distribution of GO in cement.

The addition of GO enhances the performance of cement. However, GO easily aggregates in the alkaline environment of cement, and the poor dispersion could weaken the benefits associated with the original properties of GO. The major challenge for GO-added cement is how to evenly disperse GO in the cement matrix. Thus, experimental research on solving the dispersion problem of $\mathrm{GO}$ is of great importance.

Considerable research efforts have been devoted to improving the dispersion of GO in cement. However, the well dispersion of GO in the cement matrix has not achieved. To address this issue, a few studies have proposed several methods to achieve uniform distribution. Gong et al. (1) employed a high-speed shear mixer for the mixing process to achieve an improved distribution of GO in cement paste. In addition, silica fume was utilized to improve the dispersion of GO in cement. These investigations revealed that the dispersion of GO has apparently enhanced by adding silica fume (5). A prevalent strategy in enhancing the dispersion of GO was the use of surfactant and ultra-sonication. A few research indicated that the utilization of polycarboxylate-based superplasticizer (PC) in conjunction with ultrasonic energy application could be performed to promote the uniform dispersion of GO in cementitious materials (6-9). Lv et al. (6) reported that the introduction of the PC into cement paste improved losing fluidity resulting from the larger specific surface area of GO. Metaxa (8) used four different PCs as graphene dispersant agents and investigated their efficiency. The findings proved that the PC promoted graphene uniform distribution in cement matrix. However, the studies about the impact of PC addition on the dispersion of GO are still at early stage, and the working mechanism of the PC is unclear.

This study evaluated the flocculation of GO in lime solution by carrying out the UV-Vis spectra and zeta potential investigation. Moreover, this research employed PC to disperse GO and investigated the influence of different PC functional groups on the dispersion of GO. The research could give guidance on the dispersion of $\mathrm{GO}$ in the alkaline environment of cement.

\section{EXPERIMENTAL}

\subsection{Materials}

Graphite powder (8000 meshes, $99.95 \%)$, concentrated sulfuric acid $\left(\mathrm{H}_{2} \mathrm{SO}_{4}, 98 \%\right)$, hydrochloric acid $(\mathrm{HCl}, 36 \%)$, sodium nitrate $\left(\mathrm{NaNO}_{3}\right)$, hydrogen peroxide $\left(\mathrm{H}_{2} \mathrm{O}_{2}, 30 \%\right)$, potassium permanganate $\left(\mathrm{KMnO}_{4}\right)$, calcium hydroxide $(\mathrm{CH})$, glycerin, acrylic acid and polyacrylic acid were all analytical grade. Polycarboxylate-based superplasticizer (PC, $30 \mathrm{wt}$. \%) was supplied by Sobute New Materials Co. Ltd (China).

\subsection{Synthesis of GO}

GO was prepared through a modified Hummers' method $(10,11)$. Firstly, graphite powder $(1 \mathrm{~g})$ was added into a three-necked round-bottomed flask incorporating $\mathrm{NaNO}_{3}(0.5 \mathrm{~g}), \mathrm{H}_{2} \mathrm{SO}_{4}(30 \mathrm{~mL})$, $\mathrm{KMnO}_{4}(3 \mathrm{~g})$ for $0.5 \mathrm{~h}$ mixing in an ice bath $\left(<5^{\circ} \mathrm{C}\right)$. Then the mixture was stirred at $35^{\circ} \mathrm{C}$ for $4 \mathrm{~h}$ and subsequently added by deionized water $(100 \mathrm{~mL})$. The resulting yellow suspension was mixed with $250 \mathrm{ml}$ deionized water and $5 \mathrm{~mL} \mathrm{H}_{2} \mathrm{O}_{2}$. The mixture was then filtered and washed by $\mathrm{HCl}$ solution (10 wt. \%). The remained solid was dispersed in water with a total volume of $500 \mathrm{~mL}$, forming a graphite oxide aqueous dispersion. Finally, it was purified by dialysis technology for two weeks and dispersed by sonication at $600 \mathrm{~W}$ for $1 \mathrm{~h}$. Then a stable GO suspension was obtained.

\subsection{Characterization of GO}

The specimens were dried in a vacuum environment at $45^{\circ} \mathrm{C}$ for $24 \mathrm{~h}$. The specimens were characterized by FT-IR, SEM, XRD and X-ray photoelectron spectroscopy (XPS). Fourier transform infrared (Nicolet 380 infrared spectrometer with a resolution of $0.5 \mathrm{~cm}^{-1}$ for 8 scans) was utilized to determine the 
functional groups of GO. KBr pellets were used in the analysis. Scanning electron microscopy (Zeiss EVO LS 15) was utilized to observe the microstructure of GO. Prior to the observation, the specimens were sputter-coated with gold-palladium. All images were obtained in the secondary electron mode with an electron beam of $20 \mathrm{kV}$. The XRD patterns were acquired using an X-ray diffractometer (Bruker D8 Advance from Germany, $\mathrm{Cu} \mathrm{k} \alpha, 40 \mathrm{kV}$ voltage, $40 \mathrm{~mA}$ current). The scanning speed was $6 \% \mathrm{~min}$ with a step size of $0.02^{\circ}$ in the scattering $2^{\circ}$ range of $5^{\circ}$ to $60^{\circ}$. GO samples were manually ground into fine powder, and then fixed in a metal plate. The XPS pattern was acquired using X-ray photoelectron spectroscopy (Kratos Analytical Ltd, UK) and the measurement was carried out with 4 scans per $\mathrm{eV}$.

\subsection{Dispersion of GO in $\mathrm{CH}$ solution with different reagents}

A certain concentration of $\mathrm{GO}$ suspension was employed in this study. Based on the previous research, $0.05 \mathrm{mg} / \mathrm{mL}$ was chosen as adequate concentration to study GO dispersion. Different reagents $(\mathrm{PC}$, glycerin, acrylic acid and polyacrylic acid) were added to GO suspension. Meanwhile, $\mathrm{CH}$ concentrations varied from 0 to $240 \mathrm{mg} / \mathrm{L}$. The UV-Vis spectra (Shimadzu UV 4800) and zeta potential (Zeta PALS, Brookhaven) were performed to explore the dispersion of GO in lime solution (CH solution) with different reagents. In addition, to understand the interactions between PC and GO, the FT-IR analysis was carried out.

\section{RESULTS}

\subsection{Structural characterization of GO}

The results of the FT-IR analysis of graphite and $\mathrm{GO}$ were shown in Figure 1. In the spectrum of GO, the peak at $3410 \mathrm{~cm}^{-1}$ suggested the presence of $-\mathrm{OH}$ group. The absorption band at $2856 \mathrm{~cm}^{-1}$ (symmetrical stretching) and $2921 \mathrm{~cm}^{-1}$ (asymmetrical stretching) could be caused by $-\mathrm{CH}_{2}$ group. Main peaks at $1408 \mathrm{~cm}^{-1}$ (deformation peaks of O-H groups) and $1730 \mathrm{~cm}^{-1}(\mathrm{C}=\mathrm{O}$ stretching vibration) were ascribed to $-\mathrm{COOH}$ group. In addition, the $\mathrm{C}-\mathrm{O}$ (epoxy) stretching vibration peak at $1226 \mathrm{~cm}^{-1}$, and the C-O (alkoxy) stretching vibration peak at $1052 \mathrm{~cm}^{-1}$ were confirmed. The peak at $1626 \mathrm{~cm}^{-1}$ were caused by $\mathrm{H}-\mathrm{O}-\mathrm{H}$ bending vibration. The results confirmed that graphite had the groups of $-\mathrm{CH}_{2},-\mathrm{C}=\mathrm{C}-, \mathrm{C}-\mathrm{C}$, $\mathrm{C}-\mathrm{O}$, supported by the absorption peaks at 3438 $\mathrm{cm}^{-1}, 1635 \mathrm{~cm}^{-1}, 1355 \mathrm{~cm}^{-1}, 1104 \mathrm{~cm}^{-1}$, respectively (12-14). Furthermore, the XPS result of GO (see Figure 2) depicted three strong peaks at 288.1, 286.5 and $284.6 \mathrm{eV}$, which referred to $\mathrm{C}=\mathrm{O}, \mathrm{C}-\mathrm{O}$ and $\mathrm{C}-\mathrm{C}$ groups, respectively (15-16). The results were consistent with the FT-IR measurement.

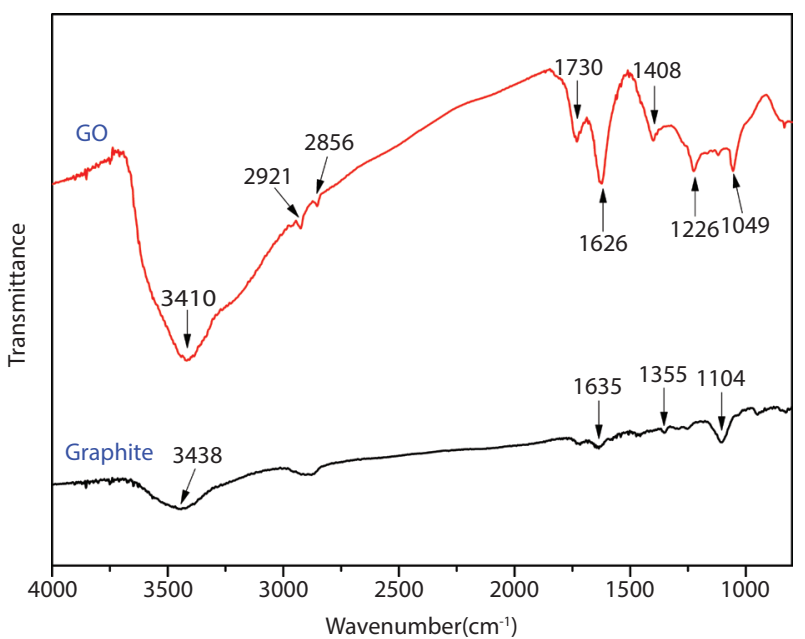

FIgURE 1. FT-IR spectra of original graphite and GO.

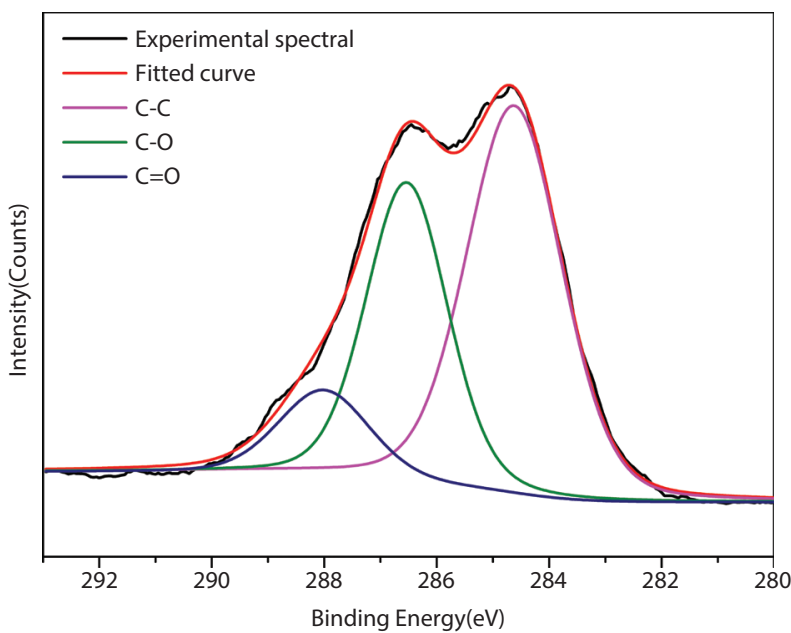

FIGURE 2. XPS spectrum of GO.

Figure 3 showed the XRD patterns of graphite and GO. The diffraction peaks (002) of graphite and GO were at $26.49^{\circ}$ and $9.64^{\circ}$, respectively. The interlayer spacing (d) could be calculated from the Bragg equation. The $\mathrm{d}_{\mathrm{GO}}$ increased to $0.92 \mathrm{~nm}$ compared with graphite $\left(\mathrm{d}_{\text {graphite }}=0.34 \mathrm{~nm}\right)$, due to the oxygen group addition during the oxidation process, which could increase the distance between the layers of GO. Figure 4 displayed SEM images of original graphite and GO. The original graphite exhibited a flake-like appearance and the surface of $\mathrm{GO}$ was rough and wrinkled.

\subsection{Flocculation of GO in $\mathrm{CH}$ solution}

Generally, in the cement hydration process, tricalcium silicate $\left(\mathrm{Ca}_{3} \mathrm{SiO}_{5}\right)$ and dicalcium silicate $\left(\mathrm{Ca}_{2} \mathrm{SiO}_{4}\right)$ formed calcium-silicate-hydrates (C-S$\mathrm{H})$ and calcium hydroxide $(\mathrm{CH})$. Tricalcium aluminate $\left(\mathrm{Ca}_{3} \mathrm{Al}_{2} \mathrm{O}_{6}\right)$ and tetracalcium aluminoferrite $\left(\mathrm{Ca}_{4} \mathrm{Al}_{\mathrm{n}} \mathrm{Fe}_{2-\mathrm{n}} \mathrm{O}_{7}\right)$ formed ettringite $(\mathrm{AFt})$, monosulphates $(\mathrm{AFm}), 3 \mathrm{CaO} \cdot \mathrm{Al}_{2} \mathrm{O}_{3} \cdot 6 \mathrm{H}_{2} \mathrm{O}\left(\mathrm{C}_{3} \mathrm{AH}_{6}\right)$ and 
$4 \mathrm{CaO} \cdot \mathrm{Al}_{2} \mathrm{O}_{3} \cdot 13 \mathrm{H}_{2} \mathrm{O}\left(\mathrm{C}_{4} \mathrm{AH}_{13}\right)$. Thus, cement paste was alkaline and special attention should be paid towards dispersing $\mathrm{GO}$ in alkaline environments (17-18). Generally, $\mathrm{CH}$ solution was used to emulate the environment generated during cement hydration.

The dispersion of $\mathrm{GO}$ was investigated in $\mathrm{CH}$ solutions at different concentrations. In this study, the concentration of $\mathrm{GO}$ was set at $0.05 \mathrm{mg} / \mathrm{ml}$. Firstly, the dispersion of $\mathrm{GO}$ in $\mathrm{CH}$ solution was visually shown in Figure 5. As the concentration of $\mathrm{CH}$ increased, the flocculation of $\mathrm{GO}$ increased significantly indicating $\mathrm{CH}$ had a remarkable effect on the dispersion of GO. GO suspension depicted a notable flocculation at the $\mathrm{CH}$ concentration of $30 \mathrm{mg} / \mathrm{L}$ compared to the plain GO suspension (Figure 5 the far left). At the same time, the cloudy GO flocculation settled down with the increasing $\mathrm{CH}$ dosage. The results were in good agreement with the conclusions obtained in other researches $(5,19,20)$.

The GO-CH flocculation and plain GO suspension were also characterized using the UV-Vis

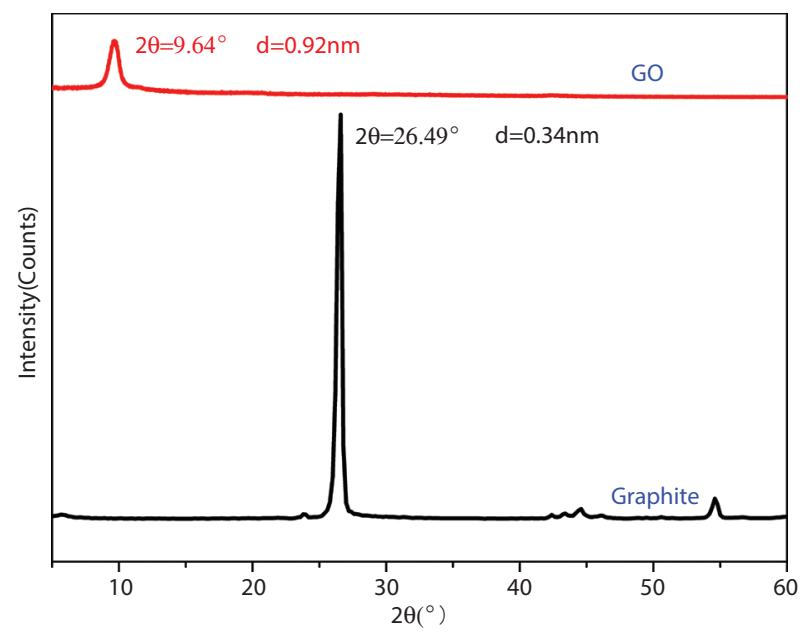

FIGURE 3. XRD patterns of original graphite and GO.

(a)

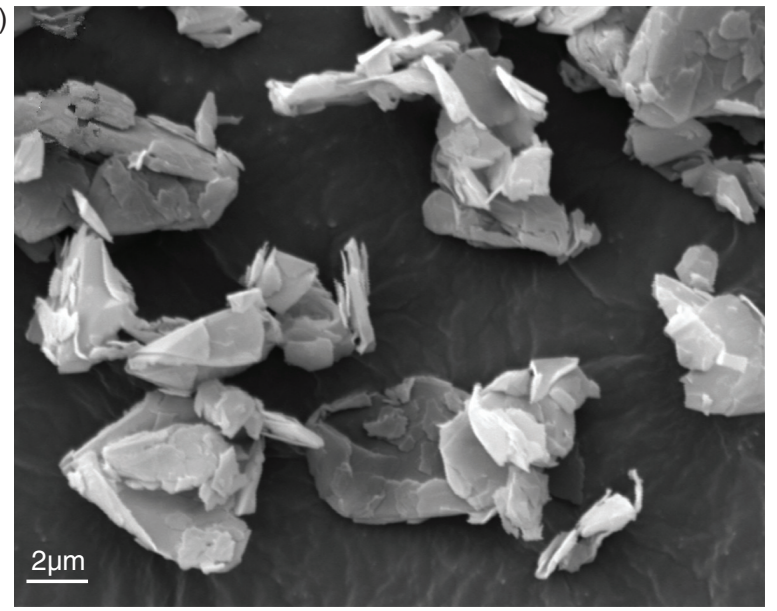

spectrum. The UV-Vis values of $\mathrm{GO}$ and $\mathrm{GO}-\mathrm{CH}$ flocculation suspensions were received after subtraction the UV-Vis values of water and corresponding to $\mathrm{CH}$ solution, respectively. The zeta potential had been applied to measure the stability of colloid. As known, the electrostatic repulsion mechanisms could enable the formation of well-dispersed GO colloids in water. Hence, the zeta potential was used to analyze GO-CH flocculation suspensions.

The UV-Vis curve of GO suspension was shown in Figure 6, and two distinct peaks were noticed. The peak at approximately $230 \mathrm{~nm}$ was caused by the $\pi-\pi^{*}$ transitions, and the shoulder vibration located at $300 \mathrm{~nm}$ was attributed to the $n-\pi^{*}$ transitions (21-22). The peak at $230 \mathrm{~nm}$ was the main characteristic peak of GO. Considering the dispersion study, the peak at $230 \mathrm{~nm}$ was selected as reasonable wave length to study the effect of $\mathrm{CH}$ on the dispersion of GO by the UV-Vis spectra.

Figure 7 showed the effect of $\mathrm{CH}$ concentrations on the dispersion of $\mathrm{GO}$ by the UV-Vis spectra and zeta potential. With the increase of $\mathrm{CH}$ concentration, the negative zeta potential increased significantly and UV-Vis values decreased sharply. This suggested that the GO-CH suspension had become increasingly unstable with the increase of $\mathrm{CH}$ content.

UV-Vis values showed a sharp decrease when the concentration of $\mathrm{CH}$ increased from 20 to 30 $\mathrm{mg} / \mathrm{L}$, and depicted relatively stable trend later. The results were consistent with the visual observation (Figure 5). Moreover, for a GO suspension of $0.05 \mathrm{mg} / \mathrm{ml}$, the measured zeta potential was approximately $-37 \mathrm{mV}$. As the concentrations of $\mathrm{CH}$ increased, the zeta potential also increased significantly. In the end, the zeta potential reached values close to zero, indicating the $\mathrm{GO}-\mathrm{CH}$ suspensions were relatively unstable. Generally, the suspension was considered to be stable if its zeta potential was more negative than $-30 \mathrm{mV}$ or more positive than $+30 \mathrm{mV}(23)$. (b)

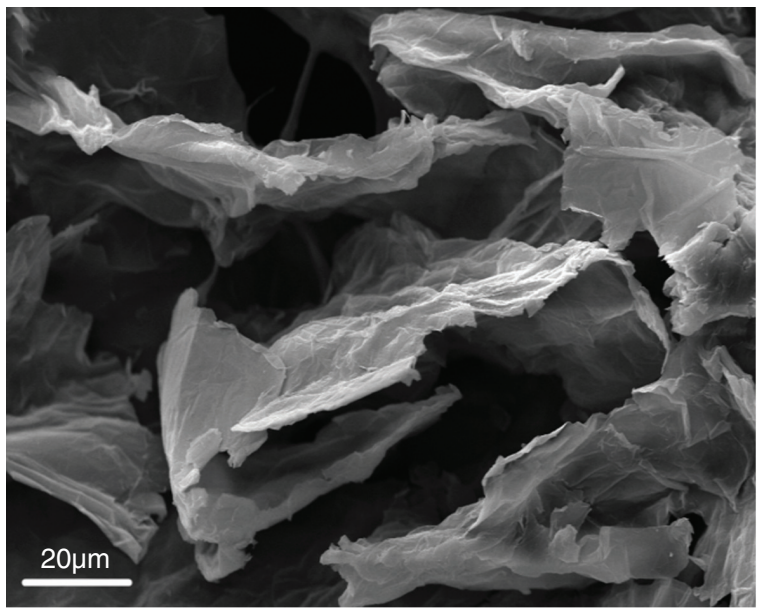

FIGURE 4. SEM images for: a) original graphite; b) GO. 


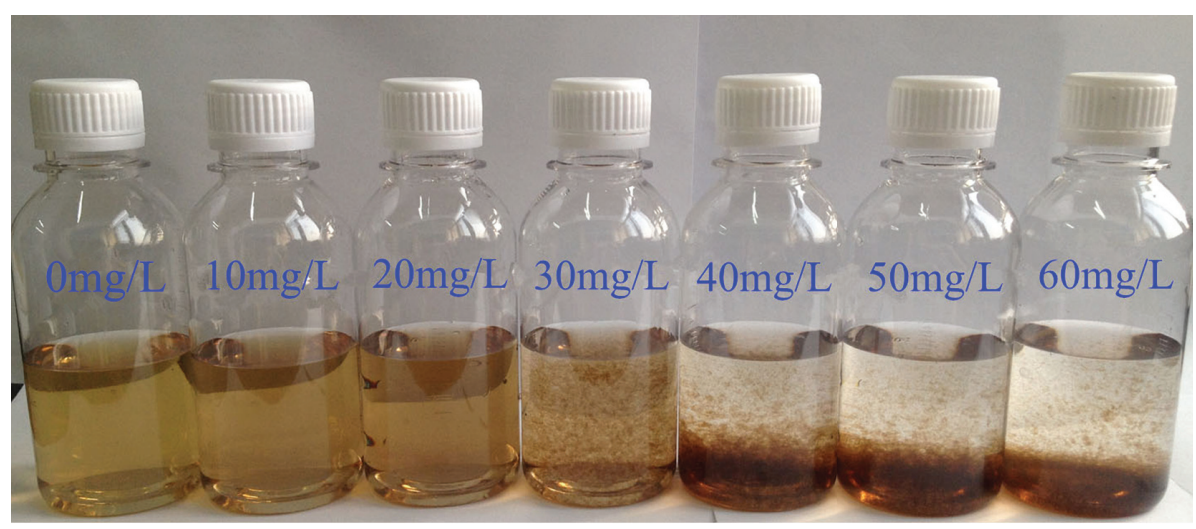

FIGURE 5. Digital images of the dispersion of GO in different concentrations of $\mathrm{CH}$ solution.

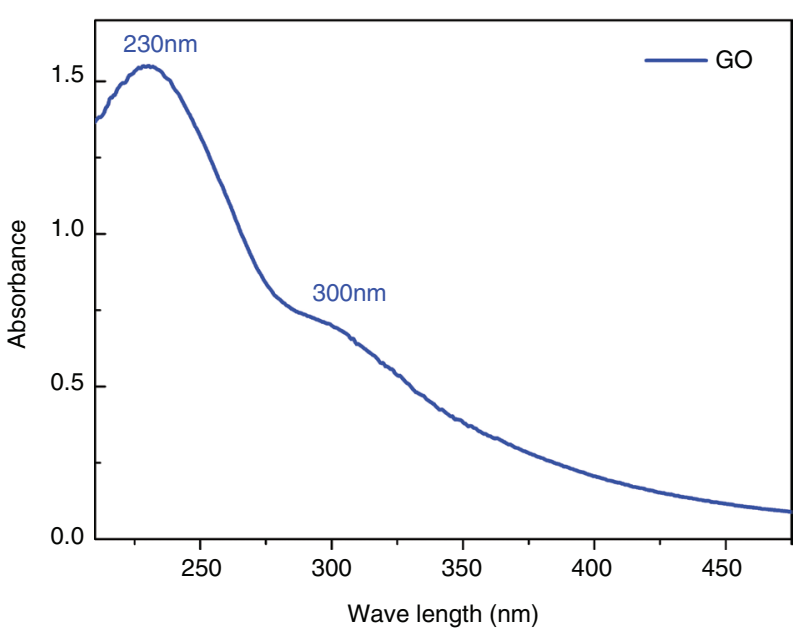

FIGURE 6. UV-Vis absorption spectrum of GO.

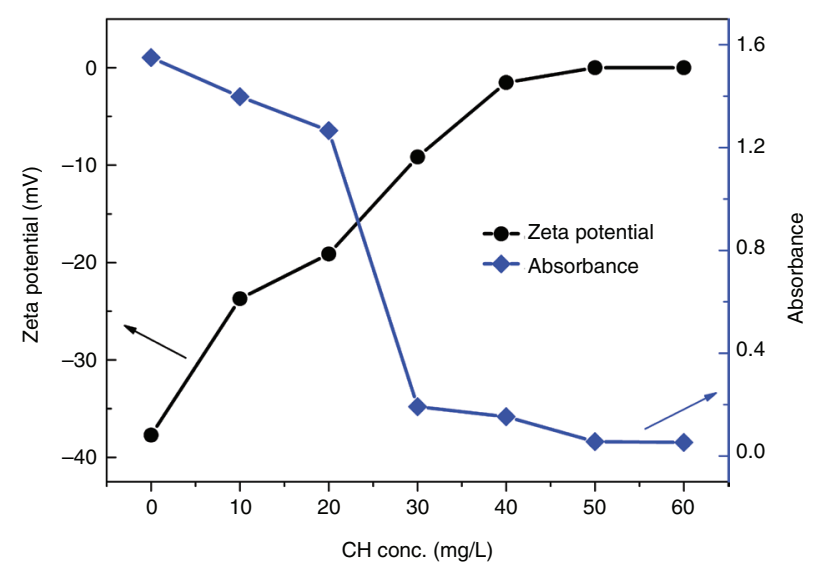

FIgURE 7. The UV-Vis absorbance and zeta potential results of $\mathrm{GO}$ in different concentrations of $\mathrm{CH}$ solution.

The addition of $\mathrm{CH}$ exhibited a negative effect on the dispersion of GO. Flocculation of GO occurred when $\mathrm{CH}$ solution was introduced with an apparently low concentration. This could be explained by the cross-linking reactions between neighboring GO sheets induced by calcium ions from $\mathrm{CH}(24,25)$.

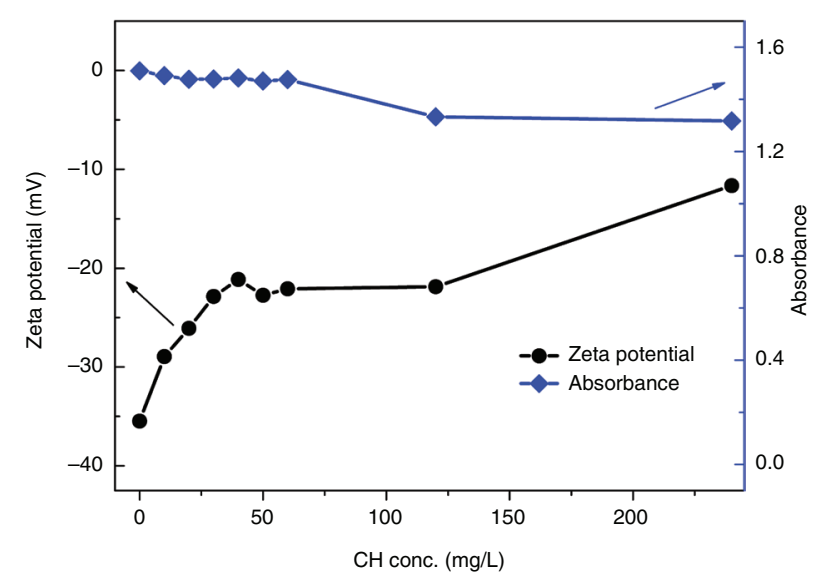

FIGURE 8. The UV-Vis absorbance and zeta potential results of GO-PC suspensions with different concentrations of $\mathrm{CH}$ (The concentrations of $\mathrm{GO}$ and PC are both $0.05 \mathrm{mg} / \mathrm{mL}$ ).

Moreover, the process of GO flocculation was very fast. This experimental result showed that the incorporation of GO directly into cement could be improper due to the appearance of $\mathrm{CH}$ produced by the cement hydration. When cement interacted with water, $\mathrm{CH}$ rapidly generated and the $\mathrm{pH}$ value rose quickly. It meant that the flocculation of GO took place before the process of absolute mixing. Thus, the effect of the mixing was limited. This phenomenon was mainly responsible for the variable behavior of cement performance mentioned early. Therefore, it was necessary to further study the dispersion of GO in cement paste.

\subsection{Dispersion of GO by $\mathrm{PC}$ in $\mathrm{CH}$ solution}

First, GO and PC were together dispersed in deionized water with continuous stirring. The content of PC was equal to the concentration of GO by weight. Then, $\mathrm{CH}$ was added into the PC/GO pre-mixture. The suspensions were subjected to the following tests. Figure 8 showed the results of $\mathrm{GO}$ dispersed by $\mathrm{PC}$ at different concentrations of $\mathrm{CH}$ solution. With the increase of $\mathrm{CH}$ concentration, UV-Vis values decreased slightly and the zeta 
potential increased. UV-Vis values exhibited no obvious differences and the zeta potential showed smaller increase when the $\mathrm{CH}$ concentrations varied from 0 to $60 \mathrm{mg} / \mathrm{L}$. When the concentrations of $\mathrm{CH}$ increased, no observable changes were recorded with UV-Vis values and zeta potential, indicating PC promoted $\mathrm{GO}$ uniform distribution in $\mathrm{CH}$ solution.

As the concentrations of $\mathrm{CH}$ moved from 60 to $240 \mathrm{mg} / \mathrm{L}$, there was a slight jump down in absorbance but it remained much higher than zero. Besides, the zeta potential value was approximately $-12 \mathrm{mV}$ when the concentration of $\mathrm{CH}$ reached 240 $\mathrm{mg} / \mathrm{L}$, which was more stable than $\mathrm{GO}$ in $\mathrm{CH}$ solution. The relatively effective dispersion of $\mathrm{GO}$ was achieved with the use of PC.

\subsection{The interaction between PC and GO by FT-IR}

In the consideration of the dispersion study of GO by PC presented above, the amount of PC was also chosen as equal to the concentration of GO by weight. Figure 9 represented the characteristic peaks of PC and PC-GO. In the FT-IR spectrum of $\mathrm{PC}$, the bands at $3430 \mathrm{~cm}^{-1}$ and $1450 \mathrm{~cm}^{-1}$ could be assigned to the vibration and deformation peaks of the -OH group, respectively. Peaks at $2897 \mathrm{~cm}^{-1}, 1635$ $\mathrm{cm}^{-1}$ and $1349 \mathrm{~cm}^{-1}$ were attributed to the stretching vibration of $\mathrm{C}-\mathrm{H}, \mathrm{C}=\mathrm{C}$ and $\mathrm{C}-\mathrm{O}$, respectively. Moreover, the bands at $1247 \mathrm{~cm}^{-1}$ (epoxy stretching vibration) and $1100 \mathrm{~cm}^{-1}$ (alkoxy stretching vibration) were due to $\mathrm{C}-\mathrm{O}$ bond. The strong absorption at $1723 \mathrm{~cm}^{-1}$ was originated from -COOH group. These observations confirmed the presence of $-\mathrm{OH}$, - $\mathrm{COOH}, \mathrm{C}-\mathrm{O}$ groups in the PC structure.

FT-IR analysis was further carried out to verify the interaction between $\mathrm{PC}$ and $\mathrm{GO}$ in the reaction process. As shown in Figure 9, with and without the presence of GO, no obvious differences could be seen at the peaks of different samples, indicating

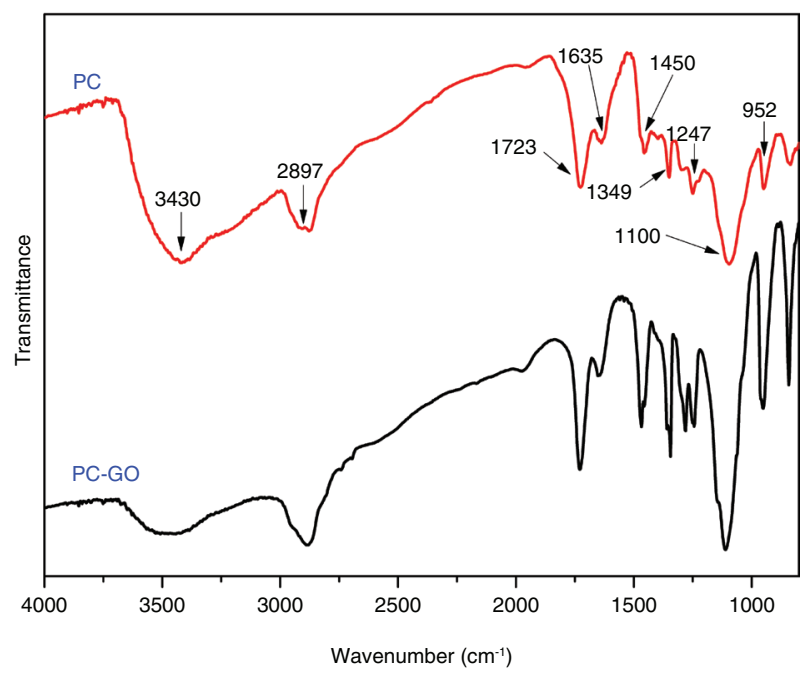

FIGURE 9. FT-IR spectra of PC and PC-GO. there was no strong chemical bond between PC and GO. The relative intensity of the bands at $3430 \mathrm{~cm}^{-1}$ (the -OH group) was clearly different. This was possibly due to the presence of weak intermolecular bonds between -COOH groups in $\mathrm{PC}$ and similar groups in $\mathrm{GO}$, which was needed to explore in depth.

In fact, $\mathrm{PC}$ had notable functional groups, such as $-\mathrm{OH}$ and $-\mathrm{COOH}$. The possible cause of a better dispersion of GO by $\mathrm{PC}$ was that the functional groups played a pivotal role in the process. Therefore, this study paid attention to the functional groups of $\mathrm{PC}$ and selected the reagent containing functional groups to carry out the research. In a typical study, glycerin and acrylic acid were used to analyze the function of $-\mathrm{OH}$ and $-\mathrm{COOH}$ groups, respectively. The primary reason for the choice was that their structures contained only a single functional group.

\subsection{The effect of different functional groups on the dispersion of $\mathrm{GO}$ in $\mathrm{CH}$ solution}

The effect of functional groups on the dispersion of $\mathrm{GO}$ in $\mathrm{CH}$ solution was investigated. Figure 10 showed the dispersion of $\mathrm{GO}$ in $\mathrm{CH}$ solution with different contents of glycerin. Two curves showed a similar trend in Figure 7. With an increase of $\mathrm{CH}$ dosage, the zeta potential increased drastically and $\mathrm{UV}-\mathrm{V}$ is values decreased. The results were consistent with the behavior found in GO suspensions with $\mathrm{CH}$. Moreover, as the weight ratio of glycerin to $\mathrm{GO}$ varied from 1 (Figure 10a) to 3 (Figure 10b), there was no significant difference between two curves. This suggested that the introduction of glycerin had little influence on the dispersion of GO in $\mathrm{CH}$ solution. The $-\mathrm{OH}$ groups did not work in the process of dispersing GO by PC.

The results of the $\mathrm{GO}$ dispersion in $\mathrm{CH}$ solution with different amounts of acrylic acid were shown in Figs. 11 (a) and (b). The effective dispersion was achieved by the incorporation of acrylic acid. When the weight ratio of acrylic acid to GO was 1 , the zeta potential and UV-Vis values kept stability until the concentration of $\mathrm{CH}$ was increased to $40 \mathrm{mg} / \mathrm{L}$. Similarly, from Figure 11 (b) with a weight ratio $3: 1$, the zeta potential and UV-Vis values showed a sharp decrease as the concentration of $\mathrm{CH}$ was increased to $90 \mathrm{mg} / \mathrm{L}$. With the addition of acrylic acid, the flocculation of GO was delayed. Moreover, with an increased amount of acrylic acid, more $\mathrm{CH}$ was needed for the flocculation of GO. The incorporation of acrylic acid had a positive effect on the dispersion of $\mathrm{GO}$ in $\mathrm{CH}$ solution. This behavior indicated that - $\mathrm{COOH}$ group was helpful in the process of GO dispersion by PC.

It was mainly because the presence of $-\mathrm{COOH}$ group improving the dispersion efficiency of PC. The primary reason for the improvement was that the $-\mathrm{COOH}$ group on the edges of the PC could react with $\mathrm{Ca}^{2+}$ and reduced the reaction chance of 

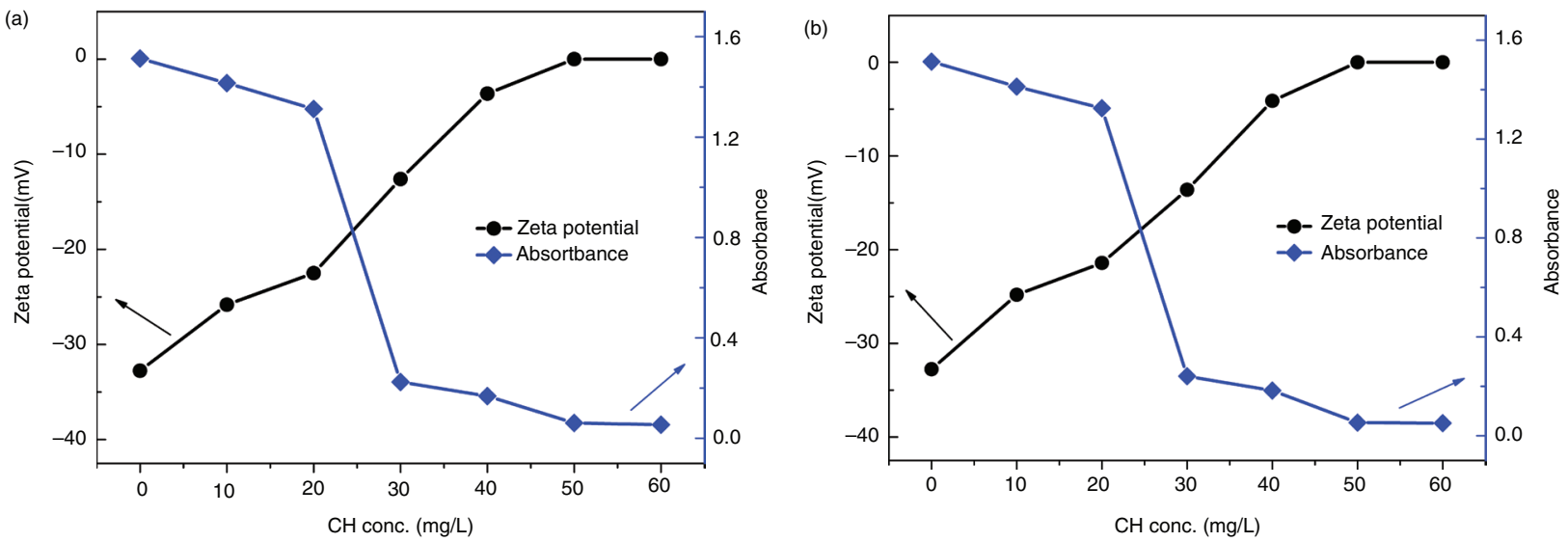

FigurE 10. The UV-Vis absorbance and zeta potential results of GO-glycerin suspensions with different concentrations of CH: (a) glycerin to GO weight ratios of 1 ; (b) glycerin to $\mathrm{GO}$ weight ratios of 3 .
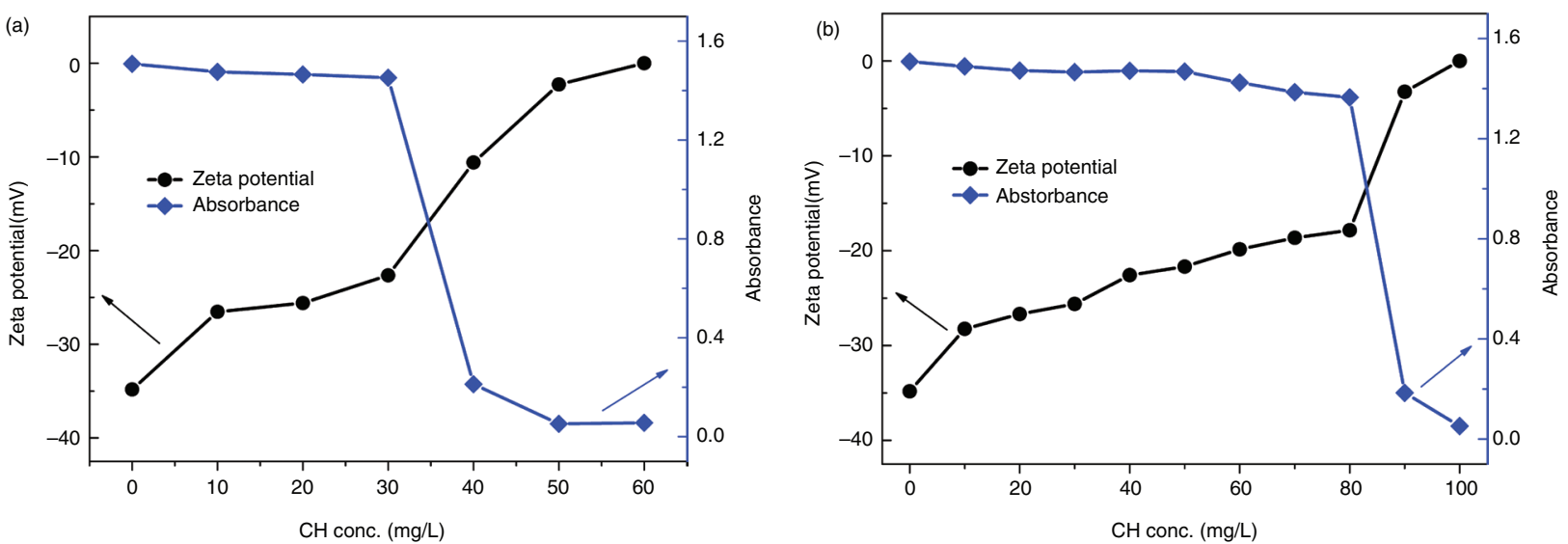

FigURE 11. The UV-Vis absorbance and zeta potential results of GO-acrylic acid suspensions with different concentrations of $\mathrm{CH}$ : (a) acrylic acid to $\mathrm{GO}$ weight ratios of 1; (b) acrylic acid to $\mathrm{GO}$ weight ratios of 3.

$\mathrm{GO}$ and $\mathrm{Ca}^{2+}$. However, the effect of acrylic acid on the dispersion of GO was relatively poor in comparison to PC. This difference possibly could be related to the special long chain molecular structure of PC. Thus, polyacrylic acid was chosen to study the effect of long chain.

Figure 12 (a) and (b) showed the dispersion of $\mathrm{GO}$ in $\mathrm{CH}$ solution with different additions of polyacrylic acid. The dispersion of $\mathrm{GO}$ in $\mathrm{CH}$ solution was improved compared with the specimens with acrylic acid. When the ratio of polyacrylic acid to $\mathrm{GO}$ was 1 , the concentration of $\mathrm{CH}$ for the flocculation of $\mathrm{GO}$ was $50 \mathrm{mg} / \mathrm{L}$. There was a slight increase compared with the specimen with acrylic acid. Analogous results were obtained at the polyacrylic acid to GO ratio of 3 . The special long chain of PC took effect in the process of GO dispersion by PC.

The overall results suggested that $-\mathrm{COOH}$ group and the special long chain of PC were properly beneficial to prevent the flocculation of $\mathrm{GO}$ in $\mathrm{CH}$ solution.

\section{DISCUSSION}

In this study, a reasonable model of explaining the dispersion mechanism of $\mathrm{GO}$ by $\mathrm{PC}$ in $\mathrm{CH}$ solution was proposed in Figure 13. First, the flocculation of GO occurred when GO directly met $\mathrm{Ca}^{2+}$. GO nanosheets connected with each other due to the chemical reactions between - $\mathrm{COOH}$ group and $\mathrm{Ca}^{2+}$. Moreover, GO achieved a relatively better dispersion in $\mathrm{CH}$ solution by adding PC. The possible reasons for this phenomenon were discussed as followed. Firstly, the - $\mathrm{COOH}$ group on the edges of $\mathrm{PC}$ could react with $\mathrm{Ca}^{2+}$. Secondly, the special long chain molecular structure of PC could separate $\mathrm{GO}$ from $\mathrm{Ca}^{2+}$ due to its steric hindrance effect. Moreover, weak intermolecular bonds between $-\mathrm{COOH}$ groups in $\mathrm{PC}$ and similar groups in $\mathrm{GO}$ might have positive effect on the de-flocculate the GO in $\mathrm{CH}$ solution. PC could wrap up $\mathrm{Ca}^{2+}$ partly and reduced the reaction chance between $\mathrm{GO}$ and $\mathrm{Ca}^{2+}$. In fact, PC played the role of sacrificial agent 

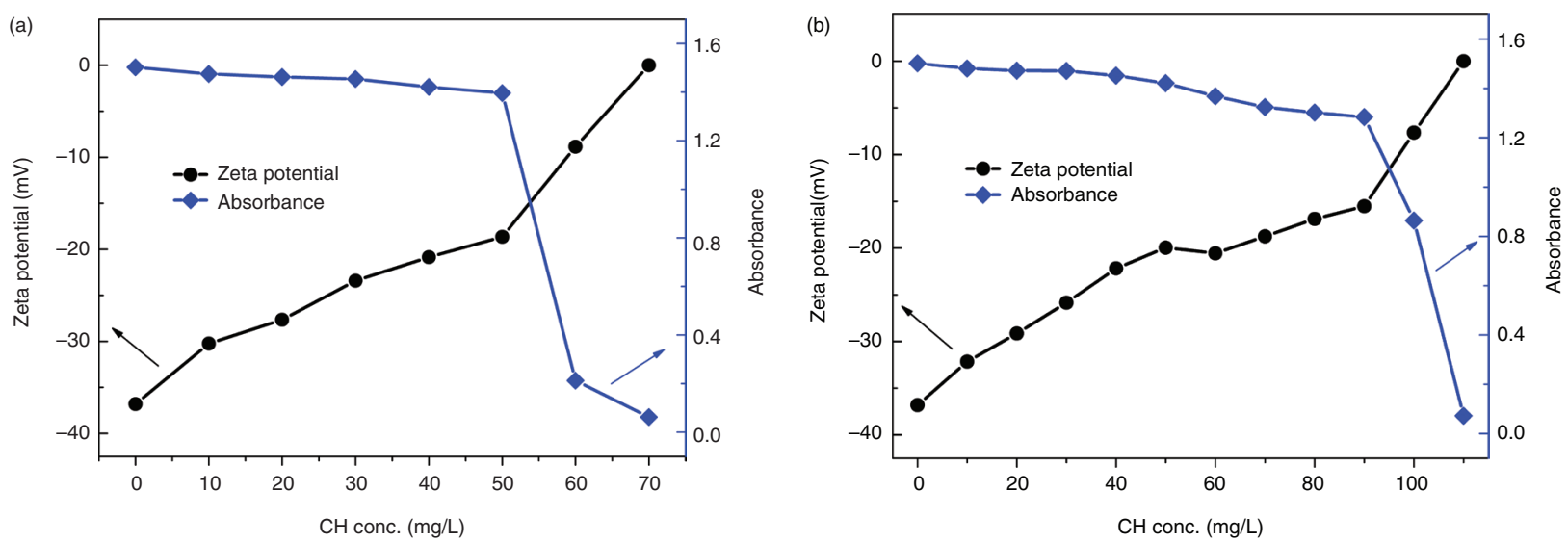

FIGURE 12. The UV-Vis absorbance and zeta potential results of GO-polyacrylic acid suspensions with different concentrations of $\mathrm{CH}$ : (a) polyacrylic acid to $\mathrm{GO}$ weight ratios of 1; (b) polyacrylic acid to $\mathrm{GO}$ weight ratios of 3.

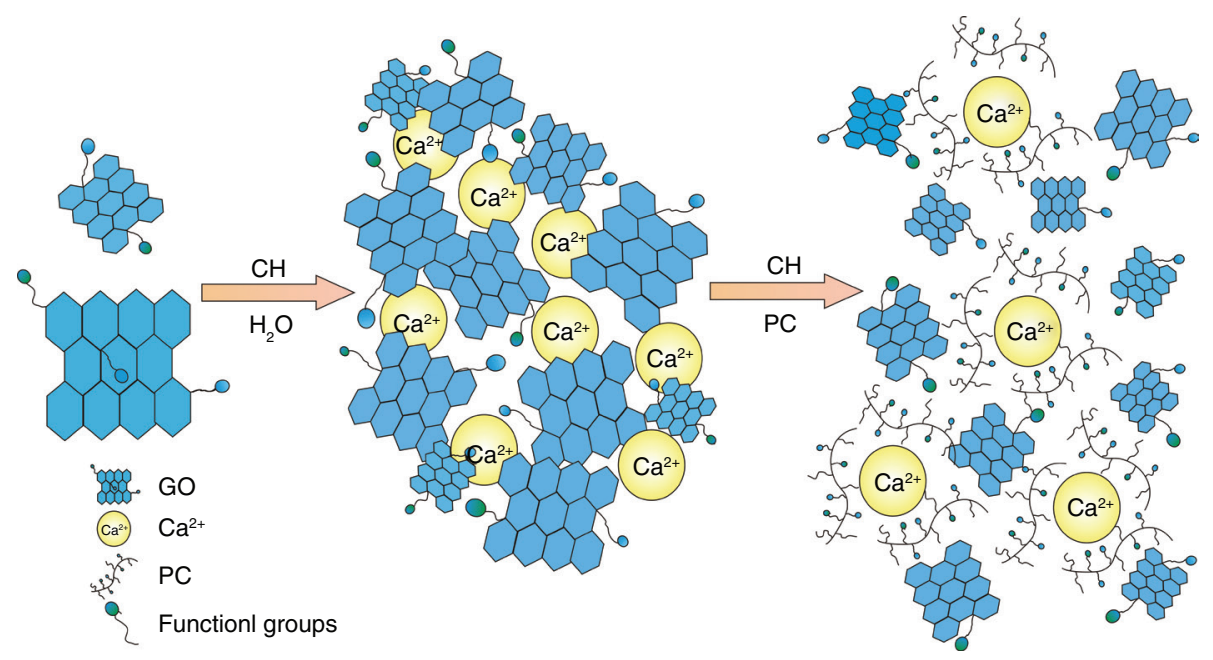

FIGURE 13. Scheme showing the dispersion of GO by PC in $\mathrm{CH}$ solution.

and improved the dispersion of $\mathrm{GO}$ in $\mathrm{CH}$ solution. The findings of this investigation may provide guidelines for delaying GO flocculation in the alkaline environment of cement paste.

\section{CONCLUSIONS}

In this paper, the flocculation of $\mathrm{GO}$ in $\mathrm{CH}$ solution and the corresponding improvement were studied experimentally. Based upon the test results, the following conclusions could be drawn:

1. An aqueous dispersion of GO was prepared with graphite oxidation and ultrasonic treatment. The FT-IR, XPS and XRD results confirmed the presence of $-\mathrm{OH},-\mathrm{COOH}$ and $\mathrm{C}-\mathrm{O}$ groups in the GO structure. The SEM image showed that the surface of $\mathrm{GO}$ was rough and wrinkled.

2. The UV-Vis spectra and zeta potential results indicated that $\mathrm{GO}$ became unstable with the increase of $\mathrm{CH}$ content. At the $\mathrm{CH}$ concentration of $30 \mathrm{mg} / \mathrm{L}$, GO suspension depicted a marked flocculation process. These results showed that incorporation of GO directly into cement was improper due to the appearance of $\mathrm{CH}$ which was produced by cement hydration.

3. The PC had an anticipated impact on the distribution of $\mathrm{GO}$ in $\mathrm{CH}$ solution. $\mathrm{GO}$ achieved a better dispersion with the incorporation of PC. Moreover, there might be weak intermolecular bonds between - $\mathrm{COOH}$ groups in $\mathrm{PC}$ and similar groups in GO.

4. The - $\mathrm{COOH}$ group was a better choice to be used as sacrificial agent than - $\mathrm{OH}$ group in terms of improving GO dispersion. In addition, the special long chain of PC also played a pivotal role in the process. These findings may be beneficial for enhancing the GO distribution in the cement paste. However, even with the improved dispersion, GO could also react with $\mathrm{Ca}^{2+}$ due to the presence of $-\mathrm{COOH}$ group on the edge. Therefore, it was necessary to modify GO in the aspects of the functional groups. 


\section{ACKNOWLEDGMENTS}

This research is financially supported by the National Nature Science Foundation of China (Grants 51272092 and 51772129), National Key Technologies R\&D Program (Grants 2016YFB0303505) and the 111 Project of International Corporation on Advanced Cement-based Materials (No. D17001).

\section{REFERENCES}

1. Gong K.; Pan Z.; Korayem A.H.; Qiu L.; Li D.; Collins F.; Wang C.M.; Duan W.H. (2015) Reinforcing Effects of Graphene Oxide on Portland Cement Paste. J. Mater. Civ. Eng. 27, A4014010. https://doi.org/10.1061/(ASCE) MT.1943-5533.0001125.

2. Pan, Z.; He, L.; Qiu, L.; Korayem, A.H.; Li, G.; Zhu, J.W.; Collins, F.; Li, D.; Duan, W.H.; Wang, M.C. (2015) Mechanical properties and microstructure of a graphene oxide-cement composite. Cem. Concr. Comp. 58, 140-147. https://doi.org/10.1016/j.cemconcomp.2015.02.001.

3. Mohammed, A.; Sanjayan, J.G.; Duan, W.H.; Nazari, A. (2015) Incorporating graphene oxide in cement composites: a study of transport properties. Constr. Build. Mater. 84(1), 341-347.https://doi.org/10.1016/j.conbuildmat.2015.01.083.

4. Rhee, I.; Lee, J.S.; Kim, Y.A.; Jin, H.K.; Ji, H.K. (2016) Electrically conductive cement mortar: incorporating rice husk-derived high-surface-area graphene. Constr. Build. Mater. 125, 632-642. https://doi.org/10.1016/j. conbuildmat.2016.08.089.

5. Li, X.; Korayem, A.H.; Li, C.; Liu, Y.; He, H.; Sanjayan, J.G.; Duan, W.H. (2016) Incorporation of graphene oxide and silica fume into cement paste: A study of dispersion and compressive strength. Constr. Build. Mater. 123, 327335. https://doi.org/10.1016/j.conbuildmat.2016.07.022.

6. Lv, S.; Ma, Y.; Qiu, C.; Sun, T.; Liu, J.; Zhou, Q. (2013) Effect of graphene oxide nanosheets of microstructure and mechanical properties of cement composites. Constr. Build. Mater. 49, 121-127. https://doi.org/10.1016/j.conbuildmat.2013.08.022.

7. Wang, B.; Jiang, R.; Wu, Z. (2016) Investigation of the Mechanical Properties and Microstructure of Graphene Nanoplatelet-Cement Composite. Nanomaterials. 6, 200. https://doi.org/10.3390/nano6110200.

8. Metaxa, Z.S. (2015) Polycarboxylate based superplasticizers as dispersant agents for exfoliated graphene nanoplatelets reinforcing cement based materials. J. Eng. Sci. and Techno. Rev. 8(5), 1-5.

9. Sharma, S.; Kothiyal, N.C. (2015) Comparative effects of pristine and ball-milled graphene oxide on physicochemical characteristics of cement mortar nanocomposites. Constr. Build. Mater. 115, 256-268. https://doi. org/10.1016/j.conbuildmat.2016.04.019.

10. Hummers, W.S.; Offeman, R.E. (1958) Preparation of graphitic oxide. J. Am. Chem. Soc. 80, 1339.

11. Lu, Z.; Hou, D.; Meng, L.; Sun, G.; Lu C.; Li, Z. (2015) Mechanism of cement paste reinforced by graphene oxide/ carbon nanotubes composites with enhanced mechani cal properties. $R S C A d v$. 5, 100598-100605. https://doi. org/10.1039/c5ra18602a.
12. Chen, W.; Yan, L. (2010) Preparation of graphene by a lowtemperature thermal reduction at atmosphere. Nanoscale. 2(4), 559-563. https://doi.org/10.1039/b9nr00191c.

13. Kothiyal, N. C.; Sharma, S.; Mahajan, S.; Sethi, S. (2016) Characterization of reactive graphene oxide synthesized from ball - milled graphite: its enhanced reinforcing effects on cement nanocomposites. J. Adhes. Sci. Technol. 30(9), 915-933. https://doi.org/10.1080/016942 43.2015.1129214.

14. Lu, L.; Ouyang, D. (2017) Properties of cement mortar and ultra-high strength concrete incorporating graphene oxide nanosheets. Nanomaterials. 7(7), 187. https://doi. org/10.3390/nano7070187.

15. Park, S.; An, J.; Piner, R. D.; Jung, I.; Yang, D.; Velamakanni, A.; Nguyen ST. (2015) Aqueous suspension and characterization of chemically modified graphene sheets. Chem. Mater. 20(21), 6592-6594. https://doi. org/10.1021/cm801932u.

16. Yang, H.; Monasterio, M.; Cui, H.; Han, N. (2017) Experimental study of the effects of graphene oxide on microstructure and properties of cement paste composite. Composites Part $A$. https://doi.org/10.1016/j. compositesa.2017.07.022.

17. Lu, Z.; Hanif, A.; Ning, C.; Shao, H.; Yin, R.; Li, Z. (2017) Steric stabilization of graphene oxide in alkaline cementitious solutions: mechanical enhancement of cement composite. Mater. Des. 127, 154-161. https://doi.org/10.1016/j. matdes.2017.04.083.

18. Li, X.; Lu, Z.; Chuah, S.; Li, W.; Liu, Y.; Duan, W. H.; Li Z. (2017) Effects of graphene oxide aggregates on hydration degree, sorptivity, and tensile splitting strength of cement paste. Composites Part A. 100, 1-8. https://doi. org/10.1016/j.compositesa.2017.05.002.

19. Wang, M.; Wang, R.; Yao, H.; Wang, Z.; Zheng, S. (2016) Adsorption characteristics of graphene oxide nanosheets on cement. RSC Adv. 6(68), https://doi.org/10.1039/ c6ra10902k.

20. Zhao, L.; Guo, X.; Ge, C.; Li, Q.; Guo, L.; Shu, X.; Liu, J. (2016) Investigation of the effectiveness of PC@, GO on the reinforcement for cement composites. Constr. Build. Mater. 113, 470-478. https://doi.org/10.1016/j. conbuildmat.2016.03.090.

21. Zhou, C.; Li, F.; Hu, J.; Ren, M.; Wei, J.; Yu, Q. (2017) Enhanced mechanical properties of cement paste by hybrid graphene oxide/carbon nanotubes. Constr. Build. Mater. 134, 336-345. https://doi.org/10.1016/j.conbuildmat.2016.12.147.

22. Luo, Z.; Lu, Y.; Somers, L. A.; Johnson, A. T. (2009) High yield preparation of macroscopic graphene oxide membranes. J. Am. Chem. Soc. 131(3), 898. https://doi. org/10.1021/ja807934n.

23. Everett; Hugh, D. (1988) Basic Principles of Colloid Science, Royal Society of Chemistry, London, (1988).

24. Park, S.; Lee, K.S.; Bozoklu, G.; Cai, W.; Nguyen, S.T.; Ruoff, R.S. (2008) Graphene oxide papers modified by divalent ions-enhancing mechanical properties via chemical cross-linking. ACS Nano. 2(3), 572-578. https://doi. org/10.1021/nn700349a.

25. Wang, M.; Wang, R.; Yao, H.; Farhan, S.; Zheng. S.; Du C. (2016) Study on the three dimensional mechanism of graphene oxide nanosheets modified cement. Constr. Build. Mater. 126, 730-739. https://doi.org/10.1016/j. conbuildmat.2016.09.092. 